\title{
Insights into web presence, online marketing and the use of social media by tourism operators in Dunedin, New Zealand
}

\begin{abstract}
This research study focused on online marketing and the use of social media by a sample of tourism operators in Dunedin in New Zealand. The aim was to identify the level of online marketing that tourism operators are currently implementing, and to inform improvements in relation to their design and implementation of strategies to enable effective online marketing and use of social media. Data were obtained from tourism operators through face-to-face interviews, online surveys, and an analysis of their online presence. The research study confirmed that, while they have a web presence, there is potential for substantially improved use of online marketing and social media to increase awareness of their products and services online.
\end{abstract}

Keywords: tourism, online, web, social media, marketing

\section{Introduction}

Technologies have disturbed the traditional business models of many industries, including retail, finance, and media. Ingram (2012), for example, refers to social media disrupting traditional business models and suggests that this has "allowed creators of connect to connect directly with their audience" (p.1). Ingram provocatively states that this has implications for other industries such as tourism.

By now, we've gotten pretty used to the disruption that the rise of the social web has created in the media industry... ...that same wave of socially-driven disruption is now moving through the rest of the economy too - particularly in services that can be easily socialized, such as the hotel business, the taxi industry or the education market. ...the writing is already on the wall: service businesses that don't use social features to lower barriers and increase efficiency will likely not survive long. (Ingram, 2012, p. 1)

The key message emerging for tourism is that having a web presence is not sufficient, and that social media is not an optional extra. The researchers drew upon their own experiences in searching, selecting and planning vacations, and understood how they enacted their selection of places to visit, where to stay, comparisons of costs, booking travel and accommodation, through to providing reviews of these after their adventures as tourists. Online access and the quality of the web presence and functionalities dominated the process and influenced their decision making. The aim of this study was to specify the level of use of online marketing of a range of tourism operators in Dunedin, New Zealand The study examined the general web presence of the tourism operators, and the social media activities of those tourism operators. The study was positioned within a contextual understanding that the Internet and new and emerging social media was transforming traditional marketing and communication strategies used by tourism operators in New Zealand. Consequently, this study sought to inform the improvement of the web presence, online marketing and use of social media by tourism operators.

Following the presentation of a review of literature relevant to developing a web presence, online marketing, social media and tourism, this paper outlines the research methodology, presents key findings, and provides implications which emerged from this study. 


\section{Literature Review - Web Presence and Online Marketing, Social Media and Tourism}

The Internet has had a tremendous impact on the way business is done in today's world (Middleton et al., 2009). It has lifted geographical barriers and provided its users with new forms of interactive media (Gay, Charlesworth, \& Esen, 2007). The tourism industry, in particular, has benefited from these new opportunities which the Internet offers (Zhou, 2004). This literature review is organised and presented in terms of web presence and online marketing, and social media and tourism.

\section{Web Presence and Online Marketing and Tourism}

Tourism products and services are generally intangible in that they cannot be easily displayed or experienced beforehand through traditional marketing mechanisms. However, the Internet enables this, for example, through virtual experiences, and potential customers can review travel products and services through the use of new media (Middleton et al., 2009). Internet users can watch videos and take virtual tours of the tourism product they are interested in, and gain insights by reading online reviews written by previous consumers. As Zhou (2004) suggests, "In other words, for the first time, the Internet has made it possible for intangible travel and hospitality products and services to be tangible" (p.8).

Online marketing is defined as describing the process of using digital media, as well as information and communications technologies (ICT) in order to deliver marketing messages. According to Mohammed et al. (2001, cited in Gay et al. 2007), it is "the process of building and maintaining customer relationships through online activities to facilitate the exchange of ideas, products and services that satisfy the goals of both parties” (p. 6). Consequently, compared with traditional marketing, online marketing offers today's businesses new opportunities to promote and distribute their products and services.

For many businesses in an online world, establishing a website often represents the first contact with online marketing and, according to Zhou (2004), the website of a business is often its most powerful online marketing tool, as it is a tool to create awareness. Moreover, it allows the business to present itself, as well as its products and services to the potential customers. Particularly, for Small and Medium Enterprises (SMEs), this provides a chance to overcome geographical barriers, market and budget limitations (Middleton et al., 2009). However, the main objective of a commercial website is the generation of sales and revenues (Gay et al., 2007). Therefore, it is important to consider one's web presence from the point of view of a website visitor because he or she is the one needed to be converted into a customer.

Taking into account the expectations and perceptions of these potential customers is inevitable (Gay et al., 2007). This means that the content of a website needs to be informative, creative and exciting. The design and functionality needs to go beyond the static nature of early attempts. Interactivity and functionalities need to be able to offer a rich range of interactivity in order to generate sales and revenues. For tourism operators, it is necessary for businesses to provide interactivity which meets a diverse range of potential customers to enable them to search and select their choice. This should involve processes through to including online booking facilities on their website. This assures that the pulling content of the website that attracts website visitors can lead to an actual profit by turning the visitor into a paying customer.

Therefore, having a web presence provides the platform for online marketing. There has been an identifiable trend which had its origins in early website design, which was largely static and did not promote return visitations and/or interactivity to more dynamic websites which have enhanced the web presence of tourism operators, and enable online marketing (Wertime \& Fenwick, 2008). 
Traditional marketing strategies evolve around the concept of 'pushing' a marketing message to a broad audience (Zhou, 2004). This means that the consumer is directly exposed to marketing messages such as messages conveyed through television and radio advertising. However, the online marketing approach differs from this, as it focuses on the customer itself and becomes customer driven. As Internet users can access information whenever, and wherever they like, they are able to decide for themselves when, how and where they access information or marketing messages. Content can be pulled by consumers according to their needs, demands, wishes and interests. In other words, the customer has control of access, and brings with it new expectations of tourism operators. Importantly, because the consumer can choose the information that will be accessed, received, and used to inform decisions by consumers, this leads to a new marketing approach called the 'pull'-strategy.

The Internet offers a wide range of new ways for users to interact with each other, with online content, as well as with businesses (Gay et al., 2007). This potential for interactivity is, according to Dann \& Dann (2001), the "greatest advantage Internet-based marketing offers" (p. 49). Marketers are now able to directly approach their potential and existing customers in order to engage them into conversations. A business can benefit from Business-to-Customer Marketing (B2C Marketing) in three main ways.

1. Communication with customers will allow the business to gain valuable information on their products and services.

Supporting Explanation:

This will enable businesses to see how customers perceive their products and services and whether or not they are satisfied with it. This might also result in new ideas for product development, since the customers might communicate about their needs and demands.

2. The communication tools can assist a business in building a customer relationship. Supporting Explanation:

Listening to customers, responding and engaging in communication through informative and appealing content can change the perception which a customer has of the business. It is a chance for businesses to provide additional value to their customers and establish a more personal relationship.

3. If a business creates compelling and interesting content for its audience, it will be able to create a community that the business can use as a resource pool. Supporting Explanation:

This might help the business grow. For these reasons, businesses need to make sure, that they engage and communicate with their customers. Marketers need to listen to their customers' needs and wants by communicating with them, not at them, as in the traditional marketing approach (Weber, 2007).

Opportunities for interactive communication are provided by social media. Social networks are seen as platforms where people who often share the same interests gather together in order to socialize, and this has the potential to assist businesses to interact with their potential customers. Traditional one-way communication from business to customer has transitioned to enable two-way communication, and multiple-way communication (Gay et al., 2007).

These developments have led to a control switch from the marketer to the consumer (Weber, 2007). The business is not able to control the content which a consumer uploads or reviews, nor can it control when, where or even if the customer consumes the information. Therefore, "simply transposing traditional marketing strategies into the world of electronic marketplaces will not work” (Dholakia, N., Fritz, Dholakia, R., \& Munford, 2002, p. 51).

Instead, it has become increasingly important for businesses to find new ways to reach their customers. Marketers need to capture the attention of their target market quickly and 
present informative and compelling content to prospects in order to spark their interest (Claxton \& Woo, 2008). Hence, communicating with customers through interactive new marketing tools forms a key factor for online marketing success for businesses. The relevance for tourism operators is obvious, as tourism relies heavily on finding new ways to expand customer reach and to gain their interest in a competitive environment with many operators in the same space.Web analytics are tools that collect and report data about the behaviour of online users in correspondence with certain websites or online advertisements (Strauss \& Frost, 2009).

While the relevance of these tracking tools might have been limited previously because they would only deliver quantitative measures, such as the number of visitors to a page, these tracking tools are now able to more comprehensively measure a diverse range of interactions between the web and the user (Gay et al., 2007) and provide data to inform strategies. To illustrate, Tuten (2008, p. 10) suggests the following examples of what web analytics have the potential to measure the specific pages a visitor views, delayed site visits, how frequently a visitor comes to a site and how long a visitor spends at a site, known as 'site stickiness', the average frequency of ad exposures, and provide data even about where on the screen the mouse moves.

Therefore, web analytics can provide both quantitative and qualitative data. The latter are very evident and used in social media. Social media metrics can provide information about user engagement with the content. Rather than measuring the path, origin and click-through patterns of visitors to the net, social media metrics provide insights into a user's interaction with the presented information. As Strauss \& Frost (2009) appropriately draw attention to this by stating that, "marketers want to know how visitors participate on the site rather than simply measuring whether or not they landed on the page" (p. 36).

This means that social media metrics focus on the participation of users in, for example, downloading, uploading, generating, reviewing or rating content (Strauss \& Frost, 2009). Furthermore, there are also specific measurements for social media advertising. For example, for performance measurements of social media advertising, examples include the metrics of Facebook. Facebook sends out weekly reports to its advertising customers with performance measurements, such as click-through which refers to the number of visitors clicking on an online advertisement, and the sales conversion rate which provides information about the number of people clicking through and completing a transaction (Tuten, 2008).

In general, measuring online marketing effectiveness supports businesses in better understandings about their target market and evaluating their marketing strategy. It will help answer questions such as whether or not the web tools or social media used are aligned successfully to the target market. Consequently, businesses can adapt their marketing strategy, for example, by customising their website or joining a different social network(Strauss \& Frost, 2009). However, according to Gay et al. (2007), many businesses do not know what to do with the collected data or do not even know what to measure because they have failed to define their marketing objectives.

Therefore, it is important for marketers to set marketing objectives and choose those web metrics that stand in correlation to their marketing strategy. They need to be clear about what the aim for their online marketing plan is, before they start measuring. For example, for a commercial website, the main objective of online marketing is probably to attract customers to their website in order to generate sales.

Consequently, online sales conversion, the percentage of visitors to the site who actually complete an online transaction, is the most relevant measurement (Tuten, 2008). Only when the objectives of the online marketing activities are set, web analytics can deliver relevant information and serve as performance measurements (Gay et al., 2007).

\section{Social Media and Tourism}


More recently, web presence and online marketing has been complemented by trends in social media in tourism. Social media has become increasingly evident through Web 2.0 developments, conceptualised as the second stage of Internet development which O'Reilly (2006) defines as "the business revolution in the computer industry caused by the move to the Internet as platform, and an attempt to understand the rules for success on that new platform Chief among those rules is this: Build applications that harness network effects to get better the more people use them" (p.1). Moreover, Tuten (2008) defines the Web 2.0 "as developments in technology employed online that enable interactive capabilities in an environment characterized by user control, freedom, and dialogue” (p.3). Both writers highlight Web 2.0 as connecting people and the people being the networks creating content and communicating. This holds implications for tourism operators, as tourism is essentially a people business.

Web 2.0, also referred to as the social web, offers the Internet user a new way of interaction and communication through social media. Social media is based on content that is generated by the user itself ('user-generated content') and includes public applications and services, such as social networking sites, video sharing platforms, virtual worlds, consumer review sites and many more. Subsequently, the user can interact with other users, edit, review or share content (Weber, 2007). For marketers, social media represents an important tool in order to communicate and engage with their customers (Gillin, 2007). Therefore, social media marketing should be included in the online marketing plan of businesses. In order to adjust their marketing approach to the online world, businesses need to start by deciding "their level of online commitment and how it compliments their traditional operation” (Gay et al., 2007, p. 3). Furthermore, it is important that businesses transform their marketing strategies to the online environment.

In a comprehensive review and of relevant literature about social media and tourism and hospitality fields from 2007-2011, Leung, Law, van Hoof \& Buhalis (2013) found that "consumer-centric studies generally focused on the use and impact of social media in the research phase of the travelers' travel planning process” (p.3). Importantly, they highlighted the finding that demonstrated "the strategic importance of social media for tourism competitiveness" (p. 3). They note that the Internet has "evolved from a broadcasting medium to a participatory platform which allows people to become the 'media' themselves for collaborating and sharing information (Li \& Wang, 2011; Thevenot, 2007)”.

To make the case of the importance of social media applications for the pre-trip phase of the travellers' travel planning process, Leung et al. (2013) refer to research by Google that shows that $84 \%$ of leisure travellers used the Internet as a planning resource (Torres, 2010, cited in Leung et al., 2013). They referred to research relating to the interesting trends in User-Generated Content (UGC) the during-trip phase and the post-trip phase of the planning process. Elsewhere, UGC, and sometimes known as consumer-generated media (CGM), has been defined as "any material created and uploaded to the Internet by non-media professionals, whether it's a comment left on Amazon.com, a professional-quality video uploaded to YouTube, or a student's profile on Facebook.” (Interactive Advertising Bureau, 2008, p. 1).

This review (Leung et al., 2013), while presenting findings a very diverse range of research, revealed a diverse range of reasons and motivations why travellers create UGC. An important understanding is that tourism operators need to understand the potential for travellers providing content, as well as their provision of tourism-operated content. For example, Leung et al. (2013) refer to the study by Yoo and Gretzel (2011) which examined 2, 671 responses from the members of a United States-based commercial online research panel. That study reported that altruistic and enjoyment motives were important drivers for online travel content contributions. Elsewhere, research had determined that posting travel-related 
UGC was driven by travellers wishing to share life experiences through social interaction (Pan, MacLaurin \& Crotts, 2007).

The authors suggest that this research is likely to be corroborated by the lived experiences of readers of this paper, when they reflect on the way in which they use social media and create online content when they travel. At a personal level, the authors note that they use Facebook and the Internet to communicate from airports using their mobile devices or use free Internet access at those airports, and subsequent holiday accommodation and destinations, to send digital images, videos, emails and text messages about their arrivals, departures, and information about their destinations. Families and friends following them on Facebook, Twitter, Instagram and other social media become recipients and co-creators of UGC created by the traveller.

Consequently, this makes the increased use of social media by the consumer more explicit to both the tourism operators and the consumer. This requires an understanding that, while the tourism operator generated content is important, particularly at the point of pre-travel, the challenge for tourism operators is to understand and capitalise upon the powerful audience reach enabled by social media, and the importance of the traveller generated content duringand post-travel.

\section{Research Methodology}

As the aim of the study was to gain insights from tourism operators, a mixed methods approach was conducted. Data were collected in 2010 from tourism operators in Dunedin in New Zealand through interviews, surveys, and online documentation analysis. This enabled enhanced validity and reliability through triangulation by the use of these three forms of data collection. The authors acknowledge that, as no research is values-free and neutral, there might be other possible interpretations. Specifically, the authors disclose that they approached the data collection and data analysis phases of the research with the following assumptions:

1. That the web presence, online marketing and use of social media operators is important in a contemporary, online, networked world; and

2. Their interpretations would be influenced by their own expectations gained through their personal use and expectations of online engagement and social media in their own lived experiences of being a tourist.

Therefore, to address these assumptions, all forms of data collected aimed to address the same research question (Yin, 2009). By using triangulation, this assists in enhancing validity and reliability of the research outcome by overcoming potential bias (Collis \& Hussey, 2003). Furthermore, it allows the researcher "to gain a broader or more complete understanding" (Veal, 2006, p.107) of the research topic. This means that the possible weakness of one data collection method can be overcome by the additional data collection methods (Veal, 2006). In conclusion, this will lead to a higher quality of the research evidence (Stake, 2010).

The interview is recognised as a form of primary data collection that allows the researcher to gain first-hand information (Gray, 2009). A total of 79 interviews with tourism operators from Dunedin in New Zealand were conducted to gain a wide range of information about their online marketing activity. Data were collected in the semi-structured interviews by asking some structured questions, informed by relevant literature and also enabling additional information to be provided through open ended questions. This facilitated this research to gain in-depth information of the online marketing activities of each of particular business studied. While collecting and analyzing data is extremely time consuming (Collis \& Hussey, 2003), the time taken was justified to gain insights from those tourism operators.

In addition to the interviews, an online survey was developed and administered to 287 Dunedin tourism operators. It was envisaged that the use of an online survey would have the advantages of ease of distribution (Sekaran, 2003), and this would also enable reminders to 
provide an additive strategy for enhancing the survey response. Consistent with the experiences of surveys with low response rates, it proved challenging to get responses. Even with an active followup approach, only 26 tourism operators provided responses, which represents a response rate of only $9 \%$. Therefore, this is a limitation of this study given this low response rate. In retrospect, as we interviewed 79 tourism operators, we might have promoted the survey during those interviews, as well as having a followup return visit to then collect the surveys. That is, implementing physical distribution with the online distribution might have had an additive effect in increasing the response rate for the surveys.

Furthermore, online documentation analysis was conducted involving a sample of 10 tourism operators, chosen at random. Analysis of their web presence was undertaken through the use of a matrix, constructed using criteria, such as the ease of navigation and online booking functionalities. To identify and analyse the use of social media of the selected tourism operators with their customers, their use of two of the most common social media platforms, Facebook and Twitter, were observed over a period of ten days.

In summary, the following key findings and discussion draws upon interviews with 79 tourism operators from Dunedin in New Zealand, responses from 26 tourism operators which was a response rate of only $9 \%$, and the online documentation analysis of the websites of a sample of 10 tourism operators.

\section{Key Findings and Discussion}

This section presents key findings and discussion of this research. These are organised and presented in relation to findings obtained from the interviews, online survey, and the online documentation analysis as outlined in the previous section.

\section{Interview Analysis}

As displayed in Figure 1, 63\% of tourism operators interviewed confirmed that they do sell their products online. Surprisingly, $4 \%$ said that this was not applicable, and the findings indicate that approximately $1 / 3$ of tourism operators studied did not have an online marketing strategy.

\section{(Figure 1)}

When asked about the effects on their business if their online marketing was stopped, the majority of respondents confirmed that a complete stop of online marketing would have a big impact on the success of their business. As shown in Figure 2, 6\% of respondents commented that if they stopped their online marketing activities, their business would fail, while a further $39 \%$ indicated that this would have a big impact on their business. However, almost one in ten tourism operators interviewed responded that it would have no impact on their business. While the study did not drill down deeper, it is speculated that these tourism operators might not have an online marketing strategy as identified in Figure 1.

\section{(Figure 2)}

In exploring the use of social media, $61 \%$ of respondents were found to use social media for their business, as shown in Figure 3 below. When considered in association with 1 out of 3 tourism operators interviewed not having online marketing, and these data showing that 1 in 4 tourism operators not using social media, there is obviously considerable scope for improvement. As it might be that some tourism operators might wish to implement social 
media strategies, the interviews probed to illuminate reasons for not using social media. The reasons provided included the following:

- The need for more knowledge and expertise about social media;

- There was some resistance to using social media as it was not seen as effective;

- Some respondents believed that social media is not serving their target market; and

- They are not allowed to use social media due to the company's policy.

(Figure 3)

The majority of tourism operators stated that they use social media to interact with their customers in order to establish a relationship with their customers (33\%), for promotion (30\%) purposes, and for information (18\%) as shown in Figure 4. However, only 5\% of respondents stated that they use social media to receive feedback from their customers.

\section{(Figure 4)}

When asked about the relative impact of online marketing when compared with traditional marketing, $57 \%$ of the interviewees identified online marketing as the bigger success factor for their business, as displayed in Figure 5. A further 20\% indicated that online marketing was equally as important as traditional marketing. Thus, similar, to the previous findings, there are some tourism operators who do not believe that online marketing is important for their business to succeed. Closer examination of the nature of those businesses, trends in their customer base, and their sustainability would be needed to corroborate their claim that they did not need online marketing. However, given the disruptive nature of online and social media implications for tourism, there is a concern here as the literature suggests that if your business is not online, it does not exist for many potential consumers. It also reflects a model which relies on a tourism operator generated communication strategy which has an opportunity cost in an environment where other tourism operators are employing, for example, UGC (Leung, et al., 2013).

\section{(Figure 5)}

The analysis undertaken identified that the majority of tourism operators continue to need to better understand their target market and evaluate their marketing strategy by taking measurements of their online marketing performance (Strauss \& Frost, 2009). Moreover, during the interviews, some respondents have stated that even they do measure their online marketing activities they do not take conclusions from these measurements. This is confirming the argument by Gay et al. (2007) that many businesses do not know what to do with the collected data or do not even know what to measure. According to Gay et al. (2007), this is the result of a missing definition of their online marketing objectives.

In addition to the online marketing measurements, only some tourism operators take separate measurements for their social media activity, as revealed through the interview analysis. These results are backed up by the survey analysis, presented in the following section, showing that none of the respondents take separate measurements for their social media activity. This illustrates that the online marketing measurements of tourism operators to inform strategy are not sufficient, allowing for improvement as an important step towards online marketing success (Gay et al., 2007).

In summary, the interviews revealed that there is considerable room for improving online marketing for approximately $1 / 3$ of the tourism operators studied, and, while the interviews 
reflected an understanding by most tourism operators that not having an online marketing strategy would have a big impact and even cause their business to fail, there was a group of tourism operators who seemed to be relying on traditional means of marketing their businesses.

\section{Survey Analysis}

A personalized email with a link to the online survey was sent out to 287 of the tourism operators. This excluded those that had already participated in face-to-face interviews. As discussed earlier, the response rate was $9 \%(\mathrm{~N}=26)$ which is very low. In retrospect, it would have been more desirable to include the 79 tourism operators interviewed in the online survey, and promote this with them. Further actions might have been implemented to have an additive effect on the response rate, such as the physical visitations, collection, and followup collection of the surveys. As displayed in Figure 6, the results show that $50 \%$ use both real time bookings and social media..

\section{(Figure 6)}

The data demonstrate that there are big gaps existing in how, and to what extent statistical information is recorded and used to inform strategy. In particular, an online marketing strategy needs to be successfully aligned with the target market to achieve positive outcomes (Gay et al., 2007). Consequently, a successful online marketing strategy aligned with the target market allows the tourism operators to reach international visitors at low cost because the Internet has overcome the geographical barriers and made information accessible worldwide (Dann \& Dann, 2001). This present's great value, since both the interview and the survey analysis showed that tourism operators identify Australia, the United Kingdom and Europe as their biggest target markets.

As demonstrated within the analysis of the interviews and the survey (as shown in Figure 6), only the minority of the tourism operators studied provide real-time booking on their homepage. In fact, even though a definition of real-time booking was provided and an explanation of the process was given to the respondents, some of them did answer the question 'Do you offer real-time booking online?' with 'Yes', even they do not provide realtime booking, as later observations revealed when following-up the interviews. This clearly demonstrates gaps in knowledge about the current online developments and shows that the majority of tourism operators are not familiar with them.

Even though launching an online booking system might not be recommended for every tourism operator, convenient online booking possibilities help to increase generation of sales (Prideaux, Moscardo, \& Laws, 2006). However, it is concerning that all three sources of evidence showed that a large number of tourism operators do not sell their products or services over the Internet, apart from some who sell them on their own website. Namely, 33\% of the respondents do not sell their products online, as the interview analysis showed. Providing no online booking possibilities, even via website of third parties, results in the loss of the chance to increase revenues (Prideaux et al., 2006).

When asked about the purpose of the use of social media, the most frequently cited purposes was for maintaining the profile of their tourism operation (27\%). The next most frequently stated purposes were gaining new customers (15\%), distribution of information (15\%), and interacting with customers (15\%).

(Figure 7) 


\section{Online Documentation Analysis}

The online documentation analysis focused on three main areas; namely, web presence, website activity, and social media activity. In order to analyze and evaluate the general web presence of the sample of 10 selected tourism operators, their Uniform Resource Locator (URL) was identified and their website was located. It was found that only one tourism operator had a URL which was difficult to remember. All of the tourism operators studied were found to be listed on NZ.com. However, only 7 of them were identified as having a listing on NewZealand.com. Both the interview and the survey analyses also found that not all of the respondents were listed on NZ.com or Tourism New Zealand's website, NewZealand.com. Both websites offer free listings for tourism businesses and often present the first online information source for domestic and international visitors to New Zealand as well as the region (Bates, 2010).

Therefore, both awareness of possibilities and development of a strategy are important here, as a listing on these websites does not involve any costs and enhances the web presence of those tourism operators. Of the 10 tourism operators analysed, 8 have were found to have more than five listings on tourism related information websites. The possibility and functionality for a customer to book the services or products of the tourism operators online, either on the tourism operator's own homepage or on websites of third parties, is provided by only 6 of the businesses.

The online documentation analysis confirmed that all tourism operators had relevant information on their website, and that 9 of the 10 websites examined were considered to provide content which was up to date. While 2 of the tourism operator websites lacked clarity in their website layout, there were major problems with the readability of the text for 4 websites, because the font colour did not adequately contrast with the colour of the background of the webpage. Furthermore, ease of navigation was evident in 8 of the 10 websites studied, with all of the tourism operators providing contact details on their websites. However, improvements could be made in ease of navigation and functionality in some sites. To illustrate, only 3 websites provided a booking enquiry form, and real-time booking in less than four clicks was offered on only 3 of the websites.

Moreover, improvements could be made to the visual content, and only 1 tourism operator had a video on their website, while all of the websites featured images. Furthermore, none of the websites seemed engaging in terms of interactivity and personal connection, with only 2 websites providing links to the social media used by the business, although 4 are currently using Facebook, and 3 are using Twitter for their business. When analyzing their Facebook activity, this research found that only 2 tourism operators were actively using their account during the period of observation.

Furthermore, during the time of observation, only 1 tourism operator uploaded a new photo album to their profile, while none of the tourism operators uploaded video content. On Twitter, only 2 out of 3 account holders among the businesses observed were active during the time of observation. Whilst the amount of tweets per day ranged from zero to six with one of the tourism operators observed, the other tourism operator's tweets ranged from zero to one. One of the tourism operators included 20 links to their homepage in their tweets and generated a high number of re-tweets during the period of observation. The other tourism operator observed showed less activity by only tweeting 1 link to a photo.

Whilst 3 businesses generated growth of their Facebook Fans during the time of observation, 1 businesses' number of Fans was consistent. On Twitter, two businesses generated a growth of Followers by 5.32 and 4.29 per cent. However, one business lost Twitter Followers. Thus, the sites studied generally showed little or no evidence of active updating of content. Importantly, the use of social media through Facebook and Twitter were found to be minimal or non-existent. 
In order to develop effective online marketing and use of social media, it is also important to consider the time spent on updating or posting information online, as well as the time spent on social media. As demonstrated within the analysis of the research, the majority of tourism operators spend around 1-5 hours a week on those tasks. A number of respondents also described their time spend on their online marketing as 'not enough', whilst others classified it as 'too much'. This confirms once again that the dedication towards online marketing amongst tourism operators varies.

\section{Conclusion and Discussion}

The review of relevant literature suggested that travellers now engage online pre-, during-, and post-travel. The key implication is that tourism operators must develop a web presence or be at risk of being considered as not existing. However, merely having a web presence is insufficient. In an increasingly online and networked world, where potential customers drive the decision making through engagement online anywhere, anytime, tourism operators should build awareness of effective online marketing, with ease of navigation, and full functionality to include online booking. In addition, the next level of understanding to have the capabilities to design and implement social media strategies which enable informed consumer-driven access to information, consumer-driven decisions, and promote consumer generated marketing and content. This design should consider the pre-, during- and post-travel phases and the opportunities which each presents.

The research data collected and analysed in this research study of tourism operators in Dunedin in New Zealand highlighted gaps in relation to the web presence of some of the tourism operators. As some believed that they did not need a web presence, there is not only room for improvement, but also the possibility that these tourism operations are 'at risk' due to the significant impact of online marketing by competitors, and the increased evidence that consumers now engage more online than in previous times. The survey analysis demonstrated that those tourism operators only list their business or services on a limited number of websites, though the website listings per tourism operator showed a wide range from only one website listing through to some tourism operators listed on 10 listings.

The survey results were consistent with the results of the interview and the online documentation analysis. They clearly demonstrated the disparity of online involvement among tourism operators. While some of the tourism operators are implementing online marketing strategies, others are not yet involved and some remain uncertain about their level of commitment towards online marketing. In addition, it demonstrates that there is a substantial knowledge gap that mitigates against tourism operators from improving their web presence and online marketing.

There are special characteristics associated with the majority of New Zealand tourism operators. They are small to medium sized enterprises (SMEs) with the majority employing fewer than 10 staff, and most of the staff are part-time staff. This employment profile also reflects supply and demand for high and low seasons in the region. Consequently, limitations towards available time and expenditure are well understood. However, this also underlines the importance of developing cost-effective approaches to web presence, online marketing and use of social media. This can help increase awareness of their business and generate sales in ways that are not human resource intensive.

The missing engagement in social media by nearly half of the tourism operators studied showed that there remains a general lack of understanding about the value of social media for individual businesses. In this context, many respondents stated that they are missing the expertise to effectively use social media for their business. When analysing the social media activity of the selected tourism operators through the online documentation analysis, results showed that only one in five tourism operators were actively using their account. This 
confirms the assumption that a high number of tourism operators do not know how to successfully use social media for their business, even they might be aware of its importance. The growth rates of Facebook Fans and Twitter Followers calculated in this context showed that active social media engagement can lead to a higher awareness of the business, and attracting more customers.

Among the respondents who use social media for their business, the study showed that they interacted on the most popular social media platforms, such as Facebook, Tripadvisor, Twitter and YouTube (Stelzner, 2010). While this ensures reaching a high number of Internet users, it does not ensure reaching a high number of potential customers (Claxton \& Woo, 2008). Results from the interview analysis showed that only $16.67 \%$ of the respondents chose a certain social media platform because it aligned with their target market. However, this information should be used to inform the social media marketing strategy of tourism operators. Furthermore, the interviews showed that the respondents mainly used social media for interacting with their customers and promoting their products and services. However, the survey results showed that most of the respondents use social media in order to maintain a profile. This demonstrates that some of the respondents lack an understanding of what social media can and should be used for.

This research has shown that the majority of these tourism operators need to improve their web presence, improve their online marketing, and their use of social media. By actively presenting themselves and engaging in the online world, they will be able to increase awareness of their products and services to potential consumers. The research results and the interpretation of the data provide sufficient evidence to highlight the importance of and need for tourism operators to design and implement a successful implemented online marketing strategy. The Internet presents the potential for significant benefits for the tourism industry. Furthermore, the influence of social media is likely to continue to grow in importance and have a greater impact on consumer behaviour.

In conclusion, this research study demonstrates the importance of transforming the current practices of many tourism operators to take advantage of the opportunities for online marketing and use of social media. This study found that many tourism operators are still struggling with these changes, and this represents a substantial challenge for most tourism operators in Dunedin in New Zealand.

Suggested areas for further research include the importance of social media in the tourism industry in the Australian and Asian markets. As these are New Zealand's closest neighbours it would be relevant to research the trends that are occurring in these regions for comparisons and differences.

\section{References}

Bates, C. (2010). Introduction. Paper presented at the Tourism New Zealand Update, Mercure Hotel. Claxton, L., \& Woo, A. (2008). How to Say It: Marketing with New Media - A Guide to Promoting Your Small Business Using Websites, E-zines, Blogs, and Podcasts. New York: Penguin Group

Collis, J., \& Hussey, R. (2003). Business Research - A practical guide for undergraduate and postgraduate students (2nd ed.). New York: Palgrave MacMillan.

Dann, S., \& Dann, S. (2001). Strategic Internet Marketing. Milton: John Wiley \& Sons

Dholakia, N., Fritz, W., Dholakia, R. R., \& Mundorf, N. (2002). Global E-Commerce and Online Marketing - Watching the Evolution. Westport: Quorum Books.

Gay, R., Charlesworth, A., \& Esen, R. (2007). Online marketing - a customer-led approach. Oxford: Oxford University Press.

Gillin, P. (2007). The New Influencers - A Marketer's Guide to the New Social Media. Sanger: Quill Driver Books.

Gray, D. E. (2009). Doing Research in the Real World (2nd ed.). London: SAGE. 
Ingram, M. (2012). Airbnb, Coursera and Uber: The rise of the disruption economy. Retrieved from http://gigaom.com/2012/10/24/airbnb-coursera-and-uber-the-rise-of-the-disruption-economy/.

Interactive Advertising Bureau. (2008). IAB Platform Status Report: User Generated Content, Social Media, and Advertising - An Overview. Retrieved from http://www.iab.net/media/file/2008_ugc_platform.pdf.

Leung, D., Law, R., van Hoof, H., \& Buhalis, D. (2013). Social Media in Tourism and Hospitality: A Literature Review, Journal of Travel \& Tourism Marketing, 30(1-2), 3-22.

Li, X., \& Wang, Y. C. (2011). China in the eyes of western travelers as represented in travel blogs. Journal of Travel \& Tourism Marketing, 28(7), 689-719.

Middleton, V. T. C., Fyall, A., Morgan, M., \& Ranchhod, A. (2009). Marketing in Travel and Tourism (4th ed.). Oxford: Butterworth-Heinemann (Elsevier).

O'Reilly, T. (2006). Web 2.0 compact definition. Trying again. Retrieved from http://radar.oreilly.com/2006/12/web-20-compact-definition-tryi.html.

Pan, B., MacLaurin, T., \& Crotts, J.C. (2007). Travel blogs and the implications for destination marketing. Journal of Travel Research, 46(1), 483-491.

Prideaux, B., Moscardo, G., \& Laws, E. (2006). Managing Tourism and Hospitality Services - Theory and International Applications. Wallingford: CAB International.

Sekaran, U. (2003). Research Methods for Business - A Skill Building Approach. New York: Wiley.

Stake, R. E. (2010). Qualitative Research - Studying How Things Work. New York: Guilford.

Stelzner, M. E. (2010). Everybody's Doing It - How Marketers Are Utilizing Social Media in 2010. Retrieved from http://socialmediagraphics.posterous.com/tag/socialmedia

Strauss, J., \& Frost, R. (2009). E-Marketing (5th ed.). Upper Saddle River: Pearson Education.

Thevenot, G. (2007). Blogging as a social media. Tourism and Hospitality Review, 7(3-4), 287-289.

Torres, R. (2010, October). Today's traveler online: 5 consumer trends to guide your marketing strategy. Paper presented at the Eye for Travel, Travel Distribution Summit, Chicago, IL.

Tuten, T. L. (2008). Advertising 2.0 - Social Media Marketing in a Web 2.0 World. Westport: Praeger.

Veal, A. J. (2006). Research Methods for Leisure and Tourism - A Practical Guide (3rd ed.). Harlow: Pearson Education.

Weber, L. (2007). Marketing to the Social web - How digital customer communities build your business. Hoboken: John Wiley \& Sons.

Wertime, K., \& Fenwick, I. (2008). DigiMarketing - The Essential Guide to New Media \& Digital Marketing. Singapore: John Wiley \& Sons.

Yin, R. K. (2009). Case Study Research - Design and Methods (4th ed.). Thousand Oaks: SAGE.

Yoo, K.H., \& Gretzel, U. (2011). Antecedents and impacts of trust in travel-related consumergenerated media. Information Technology \& Tourism, 12(2), 139-152.

Zhou, Z. (2004). E-Commerce \& Information Technology in Hospitality \& Tourism. New York: Thomson. 


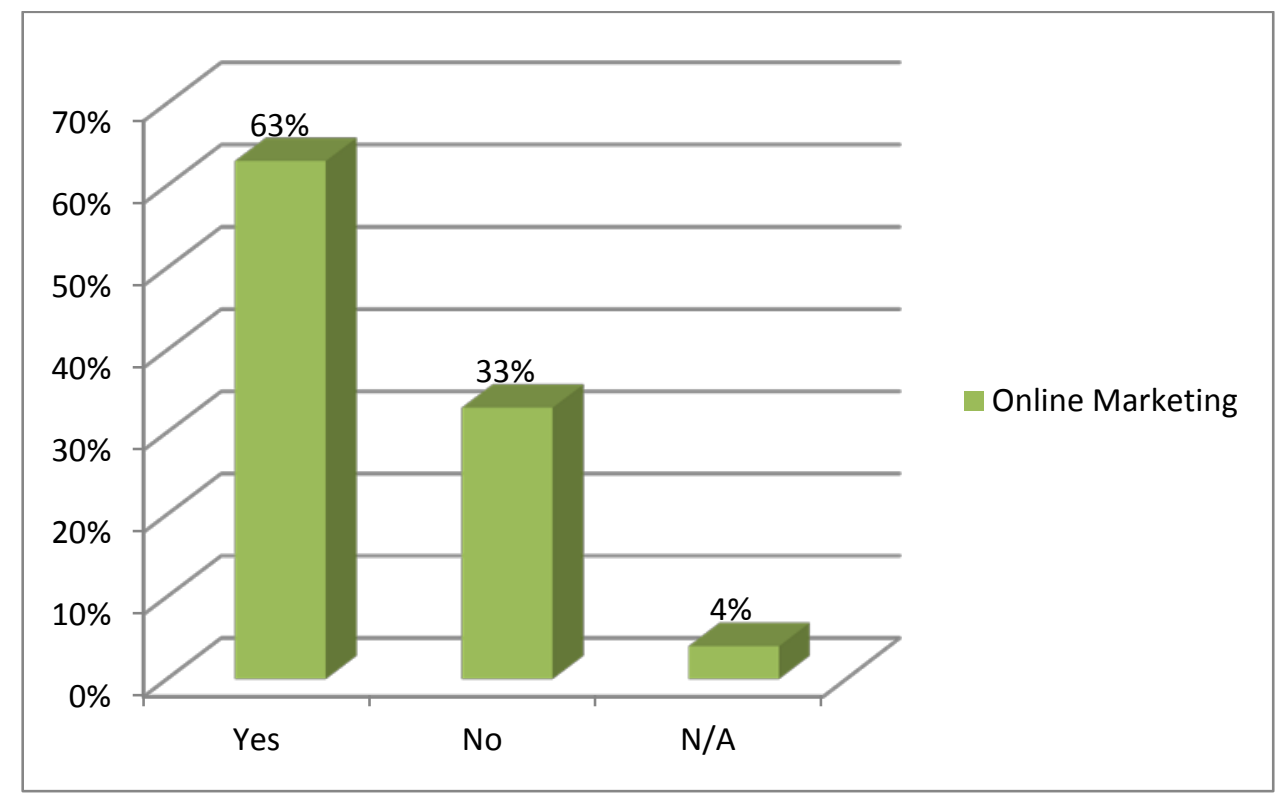

Figure 1. Online marketing by tourism operators

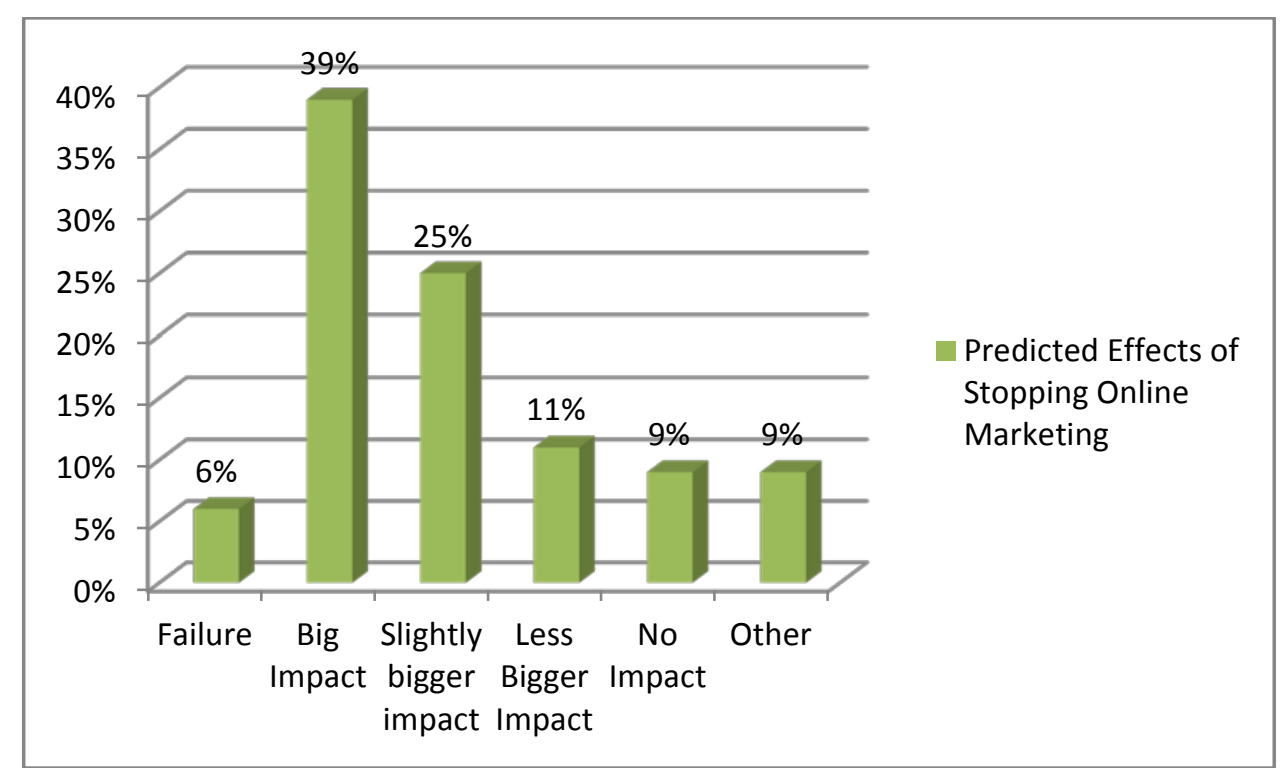

Figure 2. Predicted effects of stopping online marketing 


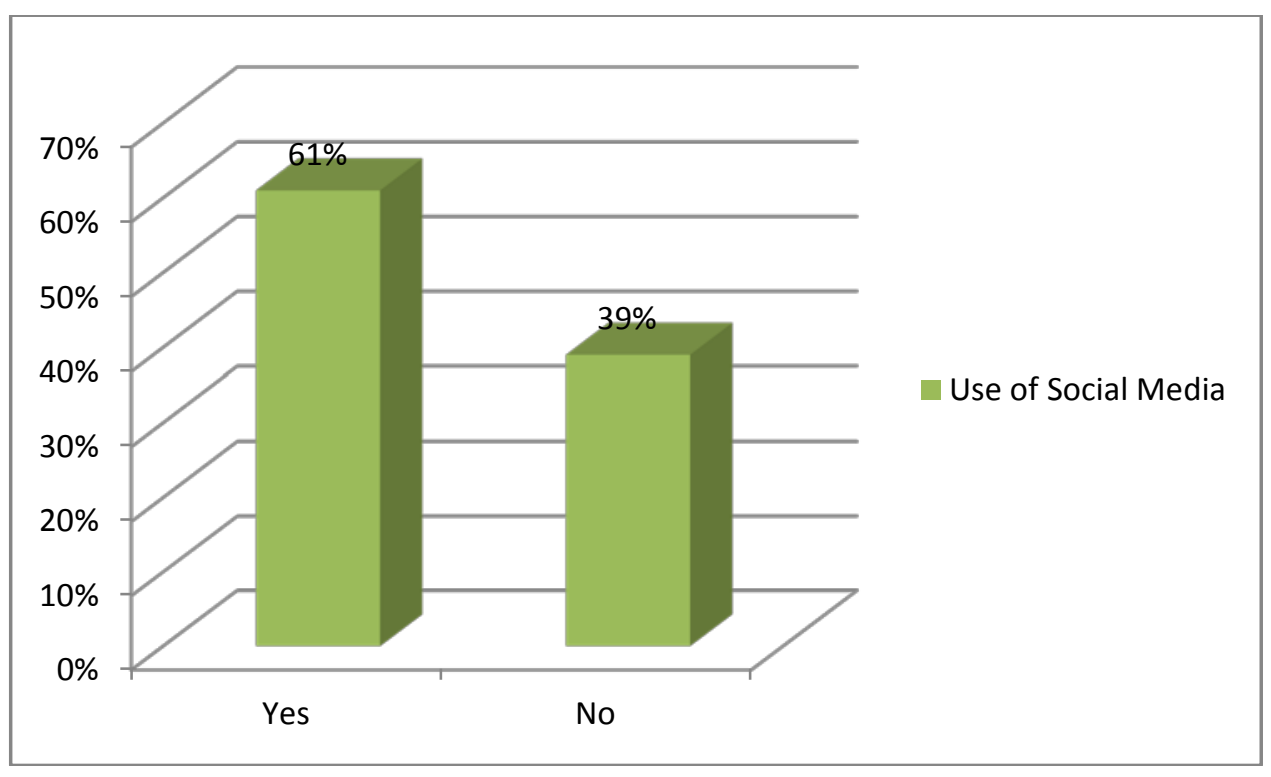

Figure 3. Use of social media

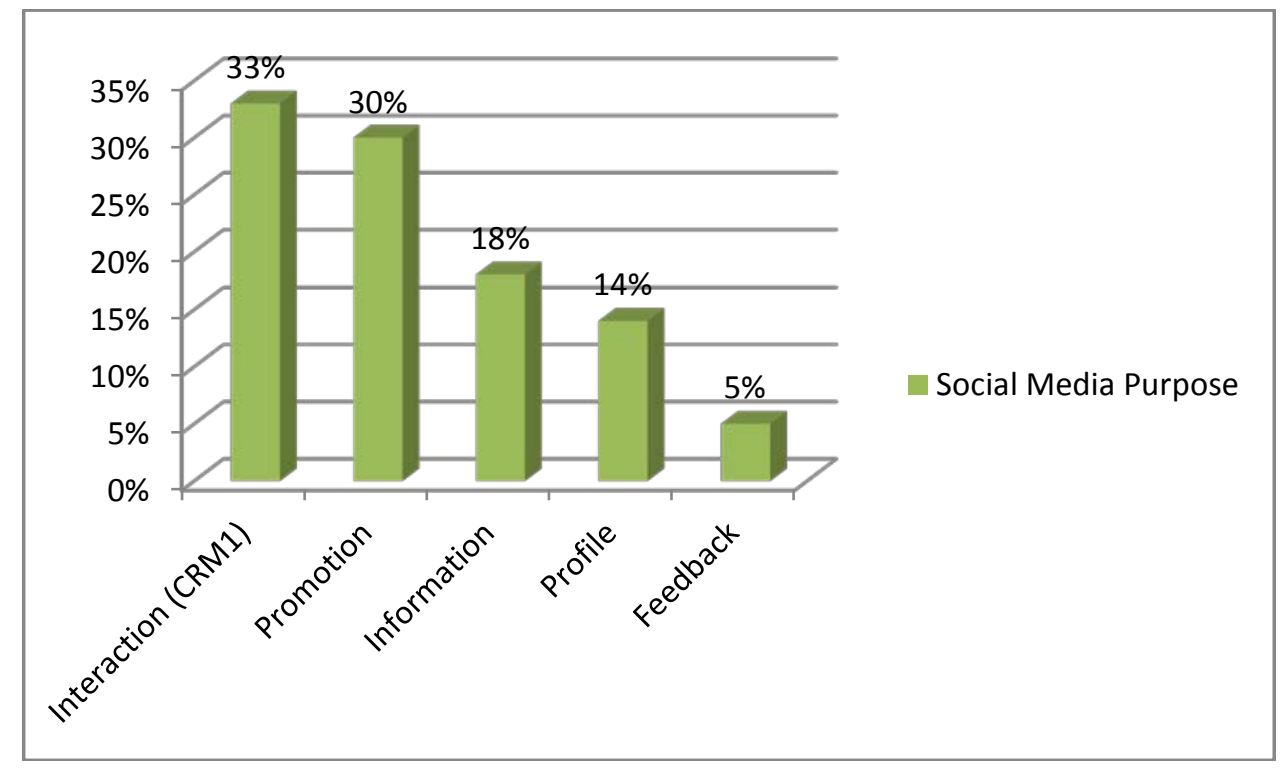

Figure 4. Social media purpose 


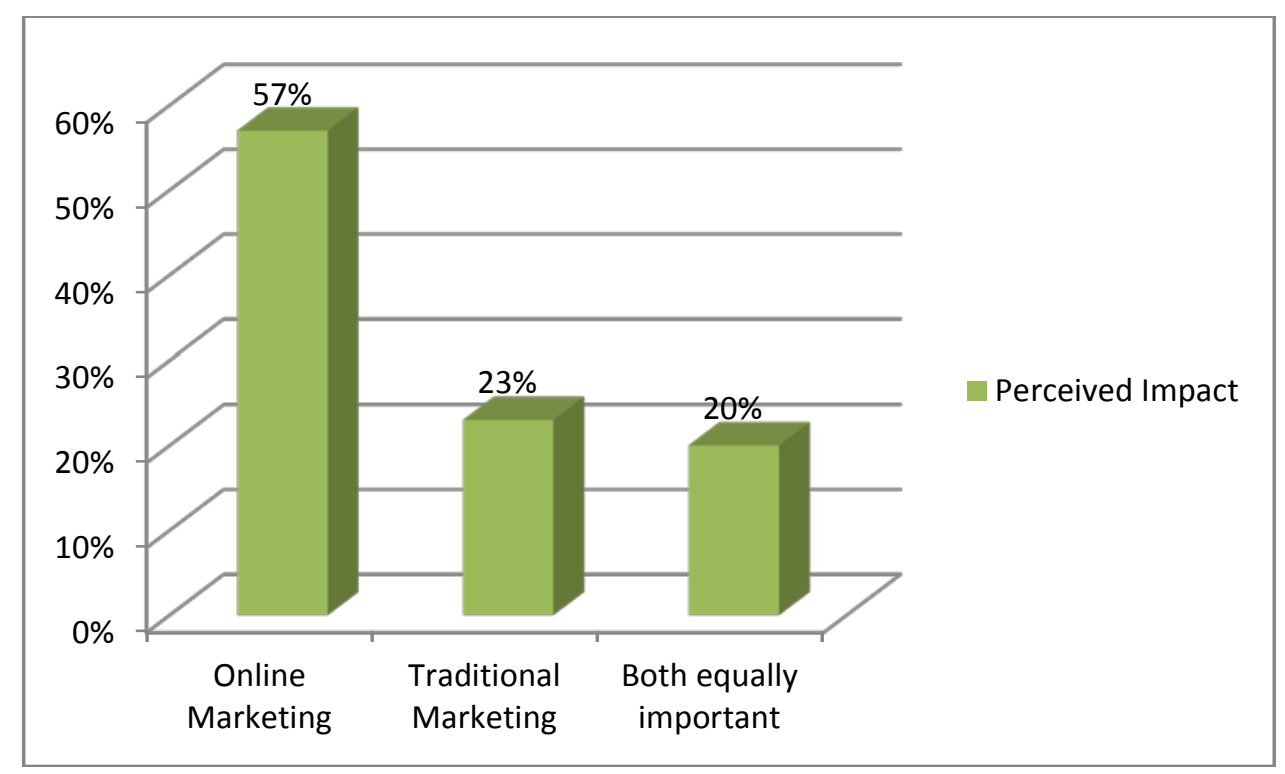

Figure 5. Perceived impact of traditional marketing and online marketing on business success

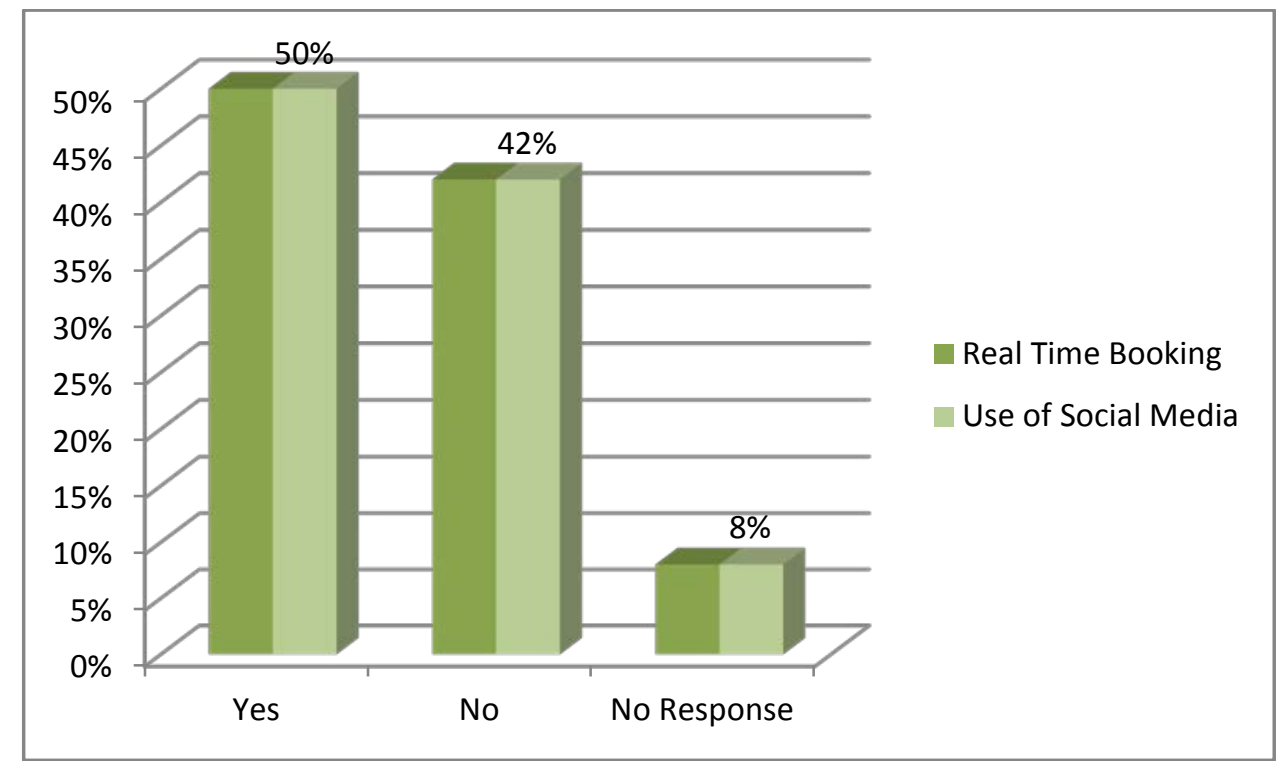

Figure 6. Real-time booking and use of social media 


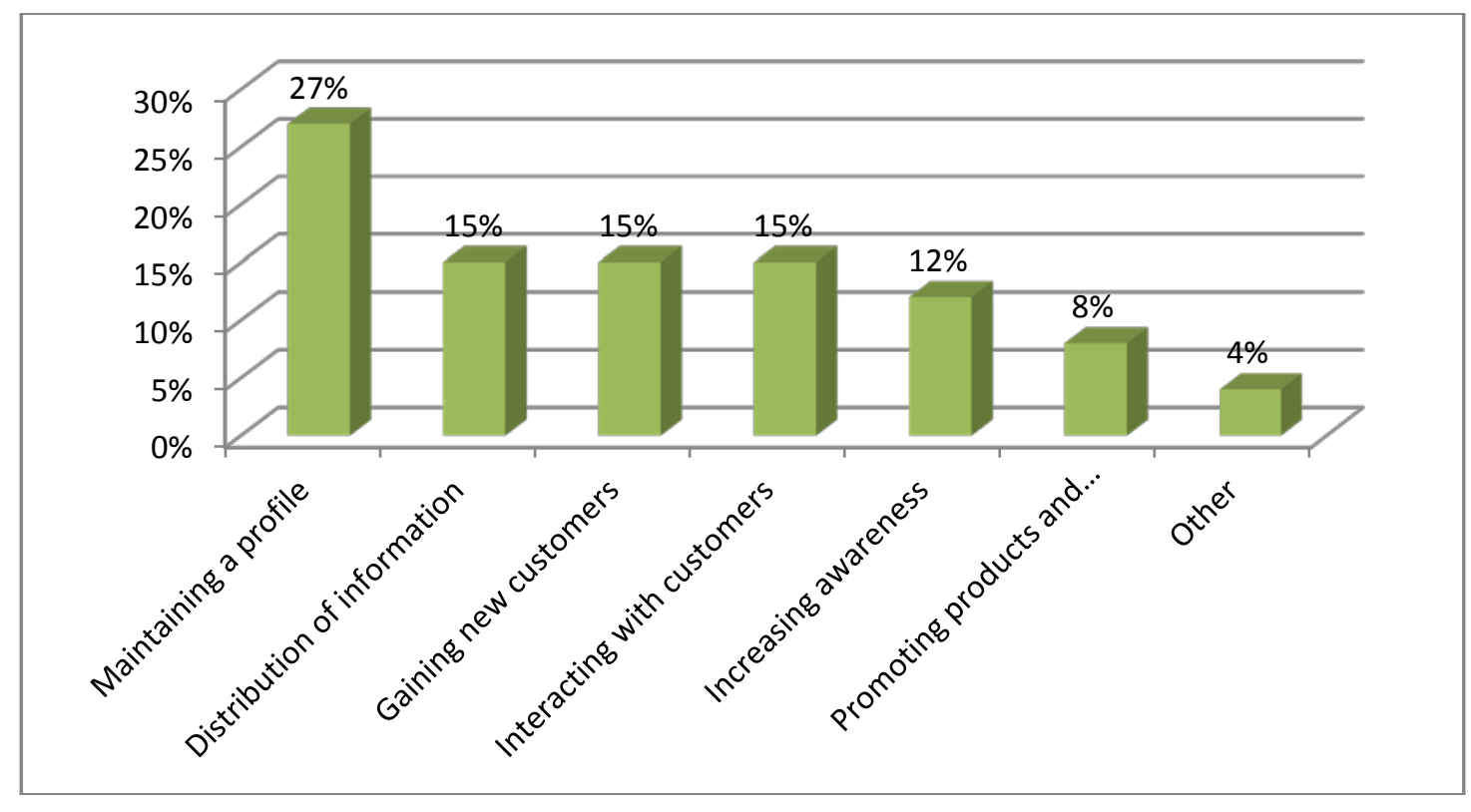

Figure 7. Purpose for using Social Media 